\title{
Erratum to: Elevated A1C is associated with impaired early-phase insulin secretion rather than insulin resistance in Koreans at high risk for developing diabetes
}

\author{
Tae Nyun Kim • Man Sik Park • Seong Keon Lee - Sae Jeong Yang • \\ Kwan Woo Lee • Moonsuk Nam • Yong Soo Park • Jeong-Taek Woo • \\ Young Seol Kim $\cdot$ Sei Hyun Baik
}

Published online: 7 July 2012

(C) Springer Science+Business Media, LLC 2012

\section{Erratum to: Endocrine}

DOI 10.1007/s12020-012-9666-3

There were some errors in the affiliations and given names of the authors in the original publication. The departmental affiliation of the fifth author should be the Department of Endocrinology and Metabolism. The given name of the sixth author is Moonsuk, and the given name of the eighth author is Jeong-Taek.

The online version of the original article can be found under doi: 10.1007/s12020-012-9666-3.

T. N. Kim $\cdot$ S. J. Yang $\cdot$ S. H. Baik $(\bowtie)$

Division of Endocrinology and Metabolism, Department of Internal Medicine, College of Medicine, Korea University Guro Hospital, 80 Guro-Dong, Guro-Gu, Seoul, 152-050, Korea e-mail: 103hyun@korea.ac.kr

\section{T. N. Kim}

Department of Internal Medicine, Cardiovascular and Metabolic Disease Center, Inje University, Busan, Korea

M. S. Park - S. K. Lee

Department of Statistics, College of Natural Sciences, Sungshin Women's University, Seoul, Korea

\section{K. W. Lee}

Department of Endocrinology and Metabolism, Ajou University College of Medicine, Suwon, Korea

M. Nam

Department of Internal Medicine, Inha University College of

Medicine, Incheon, Korea

Y. S. Park

Department of Internal Medicine, Hanyang University College of Medicine, Guri, Korea

J.-T. Woo · Y. S. Kim

Department of Internal Medicine, Kyung Hee University College of Medicine, Seoul, Korea 